REFLEXÕES SOBRE EXPERIÊNCIAS DE RACISMO INSTITUCIONAL E AMBIENTAL DE COMUNIDADES REMANESCENTES DE QUILOMBOS DO RECÔNCAVO DA BAHIA.

REFLECTIONS ON EXPERIENCES OF INSTITUTIONAL AND ENVIRONMENTAL RACISM OF REMANESCENT COMMUNITIES OF QUILOMBOS OF THE RECÔNCAVO FROM BAHIA.

Ana Paula Comin de Carvalho

Como citar este artigo:

CARVALHO, Ana Paula Comin de. Reflexões sobre experiências de racismo institucional e ambiental de comunidades remanescentes de quilombos do Recôncavo da Bahia. In: Cadernos do Lepaarq, v. XVI, n.31., p. 67-78, Jan-Jun. 2019. 


\title{
Reflexões sobre experiências de racismo institucional e ambiental de comunidades remanescentes de quilombos do Recôncavo da Bahia.
}

\author{
Ana Paula Comin de Carvalho*
}

Resumo: O artigo procura fazer algumas considerações sobre as experiências de racismo institucional e ambiental vivenciadas pelas comunidades remanescentes de quilombos do Recôncavo da Bahia e seus reflexos sobre o acesso desses grupos a bens, serviços sociais e a assunção da cidadania plena. Para tal, realizamos uma etnografia sobre os conflitos vivenciados nos processos de regularização territorial dessas coletividades tendo por base nossa experiência de pesquisa na região, dados oficiais, investigações acadêmicas, notícias de jornais, dentre outras fontes. A análise de casos exemplares revela que apesar da existência de leis e políticas afirmativas voltadas para a questão, prevalecem os interesses de grandes proprietários de terras e empreendimentos privados de interesse estatal configurando um ciclo cumulativo de danos e prejuízos a esses grupos.

\section{Palavras Chave:}

Racismo Iinstitucional; Racismo Ambiental; Comunidades Remanescentes de Quilombos; Recôncavo da Bahia

\begin{abstract}
The article tries to make some considerations about the experiences of institutional and environmental racism experienced by the quilombo remnant communities of the Recôncavo of Bahia and its reflections on the access of these groups to goods, social services and the assumption of full citizenship. To this end, we conducted an ethnography on the conflicts experienced in the processes of territorial regularization of these collectivities, based on our experience of research in the region, official data, academic investigations, news from newspapers, among other sources. The analysis of exemplary cases reveals that despite the existence of affirmative laws and policies focused on the issue, the interests of large landowners and private enterprises of state interest prevail, setting a cumulative cycle of damages and losses to these groups.
\end{abstract}

\section{Keywords:}

Institutional Racism; Environmental Racism; Remaining Communities of Quilombos; Recôncavo da Bahia.

\footnotetext{
* Professora Associada de Antropologia do Centro de Artes, Humanidades e Letras (CAHL) da Universidade Federal do Recôncavo da Bahia (UFRB). Doutora em Antropologia. Professora Permanente dos Programas de Pós-Graduação em Ciências Sociais da UFRB e Antropologia da Universidade Federal da Bahia. E-mail: apccarvalho36@yahoo.com.br
} 


\section{INTRODUÇÃO}

No presente artigo tecemos algumas considerações sobre as experiências de racismo institucional e ambiental sofridos por comunidades remanescentes de quilombos do Recôncavo da Bahia, que têm dificultado o acesso desses grupos a bens, serviços sociais e a assunção da cidadania plena. Para tanto, realizamos uma etnografia sobre os conflitos vivenciados nos processos de regularização territorial dessas coletividades. Agregamos à nossa experiência de pesquisa na região (entre os anos de 2010 a 2017) dados oficiais, estudos acadêmicos, notícias de jornais, dentre outras fontes. Deste modo, a metodologia de investigação empregada para a elaboração deste trabalho articula pesquisa etnográfica, bibliográfica e documental.

Inicialmente, cabe esclarecer ao que estamos nos referindo quando falamos sobre racismo institucional e ambiental. Compactuamos com o entendimento de que o racismo é um sistema, que se organiza e se desenvolve através de estruturas políticas, práticas e normas capazes de definir oportunidades e valores para pessoas e populações a partir de sua aparência, e que atua em diferentes níveis: pessoal, interpessoal e institucional. No nível institucional, o racismo induz, mantém e condiciona a organização e ação de instituições e políticas estatais e privadas, produzindo uma hierarquia racial. Ele é capaz de gerar e legitimar condutas excludentes, mecanismo seletivos de privilégios e barreiras que vão impregnar a cultura institucional tornando-se invisíveis aos olhos daqueles que não estão sujeitos a eles ou parte da ordem "natural" das coisas, priorizando ativamente os interesses dos brancos e simultaneamente patrocinando a negligência e a deslegitimação das necessidades daqueles identificados como não-brancos (GELEDÉS, S/D) ${ }^{1}$.

O racismo ambiental, por sua vez, engloba ações estatais ou privadas sobre o meio ambiente explicitamente racistas ou que tenham impacto racial. Os mecanismos e processos sociais movidos por esse tipo de racismo naturalizam as hierarquias sociais que inferiorizam etnias e populações tradicionais - tais como negros, indígenas, ciganos, ribeirinhos, dentre outros - e percebem como vazios os espaços físicos onde territórios estão constituídos por grupos que se caracterizam por depender prioritariamente do ecossistema no qual se inserem. A preocupação com os valores preservacionistas e ambientalistas, quando existente nesses casos, tende a ignorar essas coletividades, que se tornam alvo de políticas discriminatórias e excludentes em prol do que se convenciona ser um bem maior ou um benefício a uma parcela expressiva da sociedade (HERCULANO, 2008).

Ainda que a legislação ${ }^{2}$ e a política de regularização de territórios quilombolas ${ }^{3}$ levada a cabo pelos governos federal e estaduais se destine a corrigir uma história de desigualdades e desvantagens sofridas por esse segmento da população negra brasileira frente a um Estado nacional que o discriminou negativamente, isto é, mesmo que se configure numa ação afirmativa que visa reparar e combater o racismo nas suas diferentes expressões, sua implementação é dificultada sistematicamente pelo racismo institucional e ambiental. Antes de demonstrar como isso ocorre a partir da análise de casos específicos, se faz necessário apresentar o contexto regional no qual tais situações se inserem.

1 O racismo institucional também se dá pelo modo como o campo acadêmico produz e reproduz autores, conhecimentos e temáticas, mas devido as limitações deste artigo não abordei esses aspectos.

2 Artigo 68 ADCT/CF 1988, Decreto 4.887/2003, Instrução Normativa INCRA n. 57/2009.

3 A denominação territórios quilombolas empregada nessa passagem se refere aos espaços geográficos ocupados por coletividades que se reconhecem como quilombolas perante o Estado. Do ponto de vista antropológico, entendemos territórios quilombolas enquanto uma forma de territorialidade especifica, caracterizada pela resistência histórica de agrupamentos majoritariamente negros em manter e atualizar modos de ser e de viver num determinado espaço geográfico tendo por base relações de parentesco, compadrio e solidariedade, assim com parâmetros de moral, justiça, direito e relação com a natureza particulares. 


\section{A REGULARIZAÇÃO DE TERRITÓRIOS QUILOMBOLAS NA BAHIA E NO RECÔNCAVO:}

Embora a Bahia seja o estado brasileiro com o maior número de comunidades certificadas pela Fundação Cultural Palmares (FCP) - 619 certidões expedidas até $2017^{4}$ - e que a primeira demanda por reconhecimento estatal feita por Rio das Rãs, em Bom Jesus da Lapa, remonte a meados de 1991, as mobilizações de coletividades nesses termos no Recôncavo começaram a ocorrer apenas nos anos 2000. Para entendermos porque isso se deu dessa maneira precisamos ter em conta alguns elementos da história, economia e cultura que conformam esse espaço social.

A ocupação da região remonta ao período colonial, quando os portugueses introduziram nas terras férteis as margens do rio Paraguaçu o cultivo da cana e os engenhos de açúcar, com mão-de-obra escrava. Ao longo de quase trezentos anos, a Baia do Iguape - conformação geográfica formada pelo encontro do referido rio com o mar - foi a principal rota de transporte de alimentos e outras mercadorias do Recôncavo até Salvador (SCHWARTZ, 1988; ZAGATTO, 2013).

Boa parte da vegetação nativa, característica de Mata Atlântica, foi desmatada para dar lugar as plantações de cana, mandioca e, a partir do início do século XIX, do fumo. Contudo, as fazendas e engenhos do entorno preservaram porções de mangue, onde agricultores livres, mas principalmente escravos pescavam e mariscavam. Com o declínio das produções açucareira e fumageira, algumas dessas propriedades foram abandonadas e o comércio portuário diminuiu. As margens dos mangues, em terras antes pertencentes aos engenhos, formaram-se comunidades negras que viviam da pesca artesanal. Quando declarado o final da escravidão, muitas delas continuaram ligadas a essa atividade, como alternativa ao trabalho nos canaviais (FILHO, 2006; ZAGATTO, 2013).

Sendo assim, o êxito de fixação e permanência dessas populações nesses territórios está diretamente relacionado com a decadência econômica que atingiu o Recôncavo a partir de fins do século XIX e se intensificou ao longo do século XX ${ }^{5}$ (CARVALHO, 2014). O descaso com essas áreas antes produtivas resultante da longa crise e estagnação da região permitiu que essas coletividades não apenas constituíssem vilas, mas tivessem também liberdade de explorar os recursos naturais das adjacências por meio de atividades extrativistas e agrícolas. Em muitos casos, em virtude de acordos informais com seus proprietários, cujo interesse era manter um contingente populacional que tanto poderia servir como mão de obra barata, quanto base para a perpetuação do poder político dessas elites na localidade.

Com o passar dos anos, essas terras foram fracionadas entre novas gerações de herdeiros e/ou vendidas a terceiros. Os atuais donos não se sentiram constrangidos em perpetuar as antigas combinações que permitiam tais práticas. Seja porque não possuíam laços de qualquer natureza com os antigos senhores de engenho da região ou com os descendentes dos cativos que ali trabalhavam, ou ainda pelo fato de não partilharem da concepção de que essas propriedades deveriam ser como dádivas coletivamente compartilhadas, de maneira a assegurar a hierarquia e a dinâmica social. A premissa comum que ali se instalava segundo as novas administrações preconizava patrimônios individuais e mercantis ${ }^{6}$. O desencontro entre as perspectivas das comunidades e dos proprietários foi o estopim para o início dos conflitos territoriais vivenciados em toda a região, resultando,

4 Dados disponíveis no site da Fundação Cultural Palmares.

5 Os fatores que contribuíram para esse quadro de decadência econômica foram: o agravamento da crise nas lavouras de cana-de-açúcar e fumo resultante da concorrência de outros estados do Brasil e países; o crescimento populacional da cidade de Salvador e a elevação dos seus padrões de vida que exigiu um abastecimento mais numeroso incentivando o desenvolvimento de novas localidades de produção alimentar; e a superposição de uma rede de estradas de rodagem que privilegiou outros municípios próximos da capital em detrimento dos antigos caminhos e ferrovias do Recôncavo.

6 Consideramos, assim como Bertussi (2009), que a conjugação entre o uso comum e a propriedade privada estabelece vínculos morais e/ou sociais, na medida em que o proprietário das terras as disponibiliza para o uso coletivo. O emprego do paradigma do dom nos permite compreender melhor essa dinâmica da socialidade, em que se aliam a obrigação, a espontaneidade, o interesse e o desinteresse. Nesta perspectiva, o dom é visto como um operador privilegiado dessa socialidade. 
dentre outras coisas, na colocação de cercas em áreas que antes não as tinham ( cercamento das áreas), fixação de placas proibitivas a entrada de terceiros sem autorização dos proprietários e prisões por invasão de propriedade privada.

Atualmente, 31 comunidades encontram-se certificadas pela FCP e possuem processo de regularização fundiária em curso junto ao Instituto Nacional de Colonização e Reforma Agrária (INCRA). Como podemos observar na Tabela 1, as primeiras autoidentificações ${ }^{7}$ como quilombolas remontam ao ano de 2004. Na interação com os Sindicatos de Trabalhadores Rurais de Cachoeira e Maragojipe e com o Conselho Pastoral dos Pescadores ${ }^{8}$ (CPP), essas populações tomaram conhecimento sobre os direitos trabalhistas e previdenciários de pescadores e agricultores (como defeso de pesca e aposentadoria rural) e a legislação quilombola (ZAGATTO, 2013). A atuação desses mediadores foi o que propiciou posteriormente a leitura nativa nesse contexto específico de que ser quilombola é ser pescador, marisqueira ou lavrador. A partir de discussões realizadas no Centro de Educação e Cultura do Vale do Iguape (CECVI) é que as primeiras demandas por regularização territorial nesses termos emergiram. No ano seguinte foi formado o Conselho Quilombola do Vale do Iguape que na atualidade congrega 14 comunidades da região (CRUZ, 2012).

Tabela 1: Comunidades remanescentes de quilombos do Recôncavo em processo de regularização fundiária':

\begin{tabular}{|c|c|c|c|c|}
\hline Nome & Cidade & $\begin{array}{l}\text { Ano de certificação } \\
\text { pela FCP }\end{array}$ & $\begin{array}{l}\text { Ano de abertura do } \\
\text { processo no INCRA }\end{array}$ & $\begin{array}{l}\text { Fase da regularização } \\
\text { fundiária }\end{array}$ \\
\hline $\begin{array}{l}\text { Alto do Cruzeiro e } \\
\text { Acupe }\end{array}$ & Santo Amaro & 2010 & 2010 & Apenas processo aberto \\
\hline Baixa da Linha & Cruz das Almas & 2010 & 2011 & Apenas processo aberto \\
\hline $\begin{array}{l}\text { Brejo do Engenho da } \\
\text { Guaíba }\end{array}$ & Cachoeira & 2006 & 2012 & Apenas processo aberto \\
\hline Buri & Maragojipe & 2009 & 2010 & RTID* publicado \\
\hline $\begin{array}{l}\text { Calolé, Tombo, } \\
\text { Imbiara, Engenho da } \\
\text { Vitória e Caimbongo } \\
\text { Velho }\end{array}$ & Cachoeira & 2004 & 2009 & RTID publicado \\
\hline Cambuta & Santo Amaro & 2010 & 2010 & Apenas processo aberto \\
\hline $\begin{array}{l}\text { Caonge, Calemba, } \\
\text { Dende, Engenho da } \\
\text { Ponte e Engenho da } \\
\text { Praia }\end{array}$ & Cachoeira & 2004 & 2011 & RTID publicado \\
\hline Dende & Maragojipe & 2006 & 2011 & Apenas processo aberto \\
\hline
\end{tabular}

$7 \quad$ Na medida em que as comunidades comunicam formalmente ao Estado que se reconhecem enquanto remanescentes das comunidades dos quilombos elas são certificadas pela Fundação Cultural Palmares, órgão ligado ao Ministério da Cultura.

8 O Conselho Pastoral dos Pescadores (CPP) é uma pastoral social ligada à Comissão Episcopal para o Serviço da Caridade Solidária, Justiça e Paz da Conferência Nacional dos Bispos do Brasil (CNBB). O CPP é composto por agentes pastorais, leigos, religiosos e padres comprometidos com o Serviço junto aos pescadores e às pescadoras artesanais para a construção de uma sociedade mais justa e solidária. O trabalho pastoral com os pescadores foi iniciado em 1968, nas praias de Olinda (PE), pelo Frei Alfredo Schnuettgen. Mais tarde, ele se espalhou para os estados de Alagoas, da Paraíba e do Rio Grande do Norte. Em 1976, com apoio de Dom Helder Câmara, o CPP foi reconhecido em nível nacional pela CNBB, tendo como coordenador e animador o próprio Frei Alfredo. Assim, o conselho se expandiu para outros estados do Nordeste e para outras regiões do país, tornandose, em 1988, uma instituição jurídica.

9 O processo de regularização fundiária de territórios quilombolas se desdobra em várias fases ou etapas, desde a abertura do processo, certificação da Fundação Cultural Palmares, produção do Relatório Técnico de Identificação e Delimitação (que envolve a produção de um relatório antropológico, levantamento fundiário e consulta a órgãos públicos), publicização, prazo de apresentação e análise de contestações, emissão de portaria de reconhecimento do território e desapropriação. Trata-se de um procedimento bastante complexo e moroso, que na maioria dos casos demora anos. Para saber mais vide: http://cpisp.org.br/direitosquilombolas/caminho-da-titulacao-2/.

* $\quad$ RTDI = Relatório Técnico de Identificação e Delimitação, que abrange um conjunto diversificado de informações de ordem antropológica, histórica, econômica, social, geográfica e documental. 


\begin{tabular}{|c|c|c|c|c|}
\hline Engenho da Cruz & Cachoeira & 2007 & 2011 & Apenas processo aberto \\
\hline $\begin{array}{l}\text { Engenho Novo Vale } \\
\text { do Iguape }\end{array}$ & Cachoeira & 2005 & 2012 & 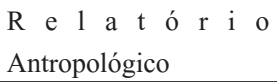 \\
\hline Enseada do Paraguaçu & Maragojipe & 2006 & 2008 & Apenas processo aberto \\
\hline Porto de Dom João & $\begin{array}{l}\text { São Francisco do } \\
\text { Conde }\end{array}$ & 2013 & 2013 & Apenas processo aberto \\
\hline $\begin{array}{l}\text { Quizanga, Guerem, } \\
\text { Baixa do Guaí, } \\
\text { Tabatinga }\end{array}$ & Maragojipe & 2006 & 2007 & RTID publicado \\
\hline Salamina Putuтији & Maragojipe & 2004 & 2005 & $\begin{array}{l}\text { Decreto Presidencial, } \\
\text { INCRA emitido na } \\
\text { posse de parte do } \\
\text { território. }\end{array}$ \\
\hline São Braz & Santo Amaro & 2009 & 2009 & 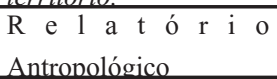 \\
\hline $\begin{array}{l}\text { São Francisco do } \\
\text { Paraguaçu }\end{array}$ & Cachoeira & 2005 & 2006 & $\begin{array}{l}\text { Portaria de } \\
\text { Re c on he cimento } \\
\text { Publicada }\end{array}$ \\
\hline São Tiago do Iguape & Cachoeira & 2006 & 2008 & 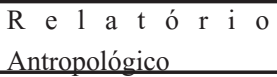 \\
\hline Tabuleiro da Vitória & Cachoeira & 2013 & 2013 & Apenas processo aberto \\
\hline Vila Guaxinim & Cruz das Almas & 2012 & 2014 & Apenas processo aberto \\
\hline
\end{tabular}

Fonte: sites do INCRA e da FCP.

Como em outros contextos de emergência de identidades quilombolas ${ }^{10}$, a mobilização das comunidades em termos étnicos foi precedida por outras formas de luta que não lograram reconhecimento pleno dos seus direitos. Nesse caso específico, foi a articulação dessas coletividades em 1997 pela criação de uma reserva extrativista (resex) na Baia do Iguape (enquanto estratégia política de enfrentamento dos danos causados pela Barragem Pedra do Cavalo instalada nessa baia em 1985); a partir dos anos 2000 pela inclusão de seus territórios (mais especificamente da Baixa do Guaí) na unidade de conservação para evitar a expropriação; ou entre 2004 e 2005 para pressionar o IBAMA a criar o conselho gestor da unidade de conservação para fazer frente aos problemas enfrentados (tais como os danos gerados pelo início das operações da Usina Pedra do Cavalo na barragem de mesmo nome). Diante da negativa do órgão ambiental em incluir essas áreas na reserva e em decorrência do contato com a legislação quilombola no processo de formação do conselho gestor da resex, os grupos começaram a demandar reconhecimento estatal nesses termos (CARVALHO e HEIMER, 2015).

Tal processo, contudo, foi extremamente turbulento. No ano de 2007, denúncias sobre fraude no procedimento de certificação da FCP envolvendo a Comunidade Remanescente de Quilombo de São Francisco do Paraguaçu, localizada na cidade de Cachoeira, ganharam espaço na mídia nacional ${ }^{11}$. Fazendeiros contrários ao processo de regularização territorial desse grupo pressionaram vários dos seus integrantes a colar cartazes nas fachadas de suas casas dizendo que não eram quilombolas e a declarar que tinham assinado a solicitação de certidão pensando que era um pedido de canoas de pesca para o governo. Mesmo depois de uma sindicância da fundação apurar que não houve irregularidades nesse caso, novos procedimentos foram estabelecidos para a obtenção da certidão de autoidentificação, com a emissão da Portaria 98 , de 26 de novembro de 2007, tornando mais burocratizada a etapa inicial do reconhecimento estatal desses grupos.

10 Estamos falando aqui em processos de etnogênese (Banton, 1977), onde as identidades se constituem num movimento dinâmico de apropriação da condição étnica e de interpretação dos eventos políticos sob um contexto de disputa territorial. Os papeis do movimento negro e de outros mediadores, como advogados e antropólogos, por exemplo, são relevantes na medida em que contribuem para a organização política desses grupos em termos étnicos com vistas a garantir direitos territoriais sobre as áreas que ocupam.

11 Em 14 de maio de 2007, o Jornal Nacional veiculou longa reportagem sobre supostas fraudes no processo de autoidentificação da Comunidade de São Francisco do Paraguaçu. Depois disso, vários outros telejornais e jornais reportaram o caso. 
A partir da emissão desta portaria, a Fundação Cultural Palmares estipulou que as comunidades tinham que enviar atas de reuniões ou assembleias de associações quilombolas realizadas para deliberar pela autoidentificação como remanescentes de quilombos com assinaturas e números de documentos da maioria dos seus integrantes, relatos sintéticos da história das comunidades contendo dados, documentos e fotografias e uma solicitação de emissão da certidão. Antes disso, o próprio INCRA poderia remeter a FCP cópia do processo de regularização fundiária do grupo para emissão da certidão, sem que sua ausência impedisse o andamento do feito. Com a emissão da Instrução Normativa do INCRA n.49, em 29 de setembro de 2008, os procedimentos de regularização só poderiam ter início após a apresentação desse documento por parte das comunidades.

Esse é um caso exemplar do modo como o racismo institucional opera a partir do estabelecimento de novos procedimentos que dificultam a plena realização dos direitos dessas coletividades ao autoreconhecimento e a regularização de seus territórios. Tais mecanismos, na prática, têm pouca ou nenhuma incidência sobre possíveis tentativas de fraudes que sequer foram verificadas numa situação específica, conforme relatado anteriormente. As visitas in loco de técnicos da instituição, procedimento utilizado em casos extremos devido ao reduzido número de servidores, seriam muito mais eficazes para averiguar prováveis irregularidades do que exigência de mais documentos e formalidades. No entanto, tais alterações têm grande impacto no tempo, documentação e custos necessários para a emissão da certidão. Principalmente tendo em vista os baixos níveis de escolaridade, renda e familiaridade desses grupos com a produção de atas e relatos que deveriam ser enviados pelo correio para a fundação, uma vez que a mesma conta com pouquíssimos escritórios regionais. Além disso, a emissão das certidões pela FCP e sua remessa as comunidades demoram meses, postergando consideravelmente a atuação do INCRA, que por si só já é morosa devido as numerosas etapas administrativas requeridas, à crescente demanda frente a escassez de pessoal e recursos, a falta de priorização da questão, o racismo institucional, dentre outros fatores.

A maior parte das comunidades listadas na Tabela 1 desenvolvem atividades de pesca, mariscagem e extrativismo na Baia do Iguape ou na Baia de Todos os Santos, que foram significativamente prejudicadas pela instalação de empreendimentos de grande porte na região nos últimos anos, tais como: o Eco-Resort Ilha de Cajaíba, no arquipélago de mesmo nome, localizado entre os municípios de Santo Amaro e São Francisco do Conde, e o Estaleiro Enseada do Paraguaçu, na cidade de Maragojipe. No entanto, para fins desse trabalho, serão abordados de maneira mais detalhada os seguintes casos das coletividades de: São Braz e São Francisco do Paraguaçu.

\section{OS CONFLITOS TERRITORIAIS DAS COMUNIDADES REMANESCENTES DE QUILOMBOS DO RECÔNCAVO DA BAHIA:}

A aquisição da Ilha de Cajaíba em 2006 por uma empresa espanhola para a construção de um Eco-Resort de luxo ${ }^{12}$, deflagrou a mobilização de várias comunidades remanescentes de quilombo pelo reconhecimento estatal de sua existência e de seus direitos territoriais e simbólicos sobre o arquipélago. O impedimento de acesso e de usufruto desse local pelos

12 A empresa de desenvolvimento Imobiliário Property Logic tem sede em Málaga, na Espanha e possui projetos de resorts de luxo no Marrocos e no Brasil. O projeto de aquisição da ilha consistia na implantação de um complexo turístico intitulado Ilha de Cajaíba Beach e Golf Resort e previa a construção de SPA hotéis, residências particulares de luxo, campo de golfe com 18 buracos, centro eqüestre, clube de pólo, piscina olímpica, academia de tênis, estádio de futebol, marina, clube náutico, lojas e vilas de entreterimento. Seu desenvolvimento ocorreria em quatro etapas e tinha a expectativa de gerar 6 mil empregos diretos. Em 2009, o Rezidor Hotel Group, associado à grife italiana Missoni, anunciou a construção de um hotel de luxo para este complexo com inauguração prevista para 2015. O hotel contaria com 118 habitações e 32 vilas. Em setembro de 2012, o grupo Property Logic anunciou o cancelamento do projeto Cajaíba Beach e Golf Resort em virtude da crise financeira internacional. Um dos proprietários do empreendimento revelou que mantinha a intenção de construir um resort com 50 apartamentos e 50 bangalôs em sociedade com empresários russos. 
integrantes dessas coletividades, que passou a vigorar a partir das notícias da instalação do empreendimento turístico na área, configurou uma ameaça a reprodução social e simbólica das mesmas.

A ilha - que ocupa um lugar singular na memória coletiva ${ }^{13}$ por ser um local de martírio de escravos ${ }^{14}$ - também tem grande importância econômica para esses grupos. Ela é fonte dos frutos (cajá, goiaba e jenipapo, jaca, saputi, coco, tamarindo, manga, banana, cacau, araçá, licuri e dendê) que são coletados para comercialização in natura, na forma de polpa ou azeite, e nas imediações de Cajaíba peixes, camarões e mariscos se reproduzem. A Comunidade Remanescente de Quilombo de São Bráz, distante doze quilômetros da sede do município de Santo Amaro, composta por 196 grupos familiares, que perfazem mais de 742 pessoas, pleiteia o arquipélago como parte do seu território, ainda que reconheça que o mesmo é utilizado por outras coletividades da região (tais como Porto de Dom João e Acupe, por exemplo) e esteja disposta a compartilhar o seu uso com elas (CARVALHO, 2016).

Tal qual indicado por O’Dwyer (2005), a identidade quilombola emerge como resposta atual diante de uma situação de conflito e confronto com grupos sociais, econômicos e agências governamentais que passam a implementar novas formas de controle político e administrativo sobre os territórios ocupados por populações afro-brasileiras. A necessidade desses grupos possuírem uma identidade singularizante é contemporânea aos processos de contato interétnico e às tentativas de esbulho dos territórios tradicionalmente ocupados.

Os conflitos com empreendimentos que prejudicam o meio ambiente e recursos naturais dos quais dependem para sobreviver não são algo recente na vida dos moradores de São Bráz. Desde a década de 60 a Companhia Brasileira de Chumbo começou a operar no município, sob a forma de uma usina produtora de lingotes desse material. Em 1989 a empresa foi vendida e incorporada a Plumbum Mineração e Metalurgia, encerrando as suas atividades em 1993. O processo metalúrgico adotado na indústria ocasionou a contaminação de todo o ambiente (ar, solo, água, animais e humanos), devido a tecnologias que não previam o controle seguro sobre os efluentes líquidos e gasosos. Além disso, a escória da produção dos lingotes de chumbo foi depositada criminosamente a céu aberto, sem qualquer tratamento, o que motivou sua utilização como material para pavimentação de ruas, jardins e pátios de escolas. Apesar de várias pesquisas acusarem a contaminação por chumbo da população de Santo Amaro, nenhuma iniciativa para tratar ou reparar os danos causados foi implementada (PORTO, PACHECO e LEROY, 2013). Esse é um tema tabu entre pescadores e marisqueiras de São Braz e de toda a cidade. Para comercializarem peixes e mariscos em feiras e para a comunidade externa, eles omitem o local de procedência dos mesmos. Embora cientes dos possíveis efeitos nocivos, eles continuam consumindo esses alimentos por falta de alternativas. O caso é um dos exemplos mais emblemáticos do mapa de conflitos envolvendo injustiça ambiental e saúde no Brasil, produzido pela FIOCRUZ e FASE ${ }^{15}$.

No fim dos anos 60, os quilombolas de São Bráz passaram a ter que conviver com a Penha Papéis, fábrica de papel reciclado, que se instalou nas imediações, colocando abaixo os roçados dos seus integrantes para o cultivo de bambus e despejando resíduos em maior ou menor quantidade nos afluentes próximos. Tais ações reduziram a área ocupada pelo grupo, suas atividades de subsistência (desde então não há mais espaço para as roças), assim como provocaram a morte de mariscos e

13 Tomamos aqui a memória coletiva nos termos propostos por Halbwachs (2004): enquanto uma imagem partilhada do passado que é lócus de ancoragem da identidade do grupo, assegurando sua continuidade no tempo e no espaço.

14 A ocupação do arquipélago remonta aos tempos coloniais. A família Argolo construiu no local um sobrado e engenho no Século XVIII e um de seus membros, Alexandre Gomes de Argolo Ferrão (1800-1870), recebeu o título de Barão de Cajaíba em 1841. Ele fícou famoso na região por sua crueldade com os escravos e inimigos a partir da prática de jogá-los, ainda vivos, num fosso da ilha. Deste modo o local representa uma parte importante da história de sofrimento e resistência das comunidades quilombolas oriundas dos antigos engenhos da região.

15 PORTO, Marcelo F.; PACHECO, Tania; LEROY, Jean P. Injustiça ambiental e Saúde no Brasil: o mapa de conflitos. Rio de Janeiro: Ed, FIOCRUZ, 2013. 
peixes em decorrência do aumento gradativo da poluição de rios e mangues que circundam o território da coletividade, o que influi diretamente na subsistência dessa população. A retirada de tocos de bambus para a fabricação de palitos para espetinhos de churrasco ou queijo coalho assado é uma atividade - mal remunerada e perigosa tanto no que se refere a aquisição da matéria-prima quanto a confecção dos palitos em si - desenvolvida por vários moradores e constitui renda principal ou complementar a advinda da pesca e a mariscagem (CARVALHO, 2016a).

Contemporaneamente, a Prefeitura Municipal de Santo Amaro aluga um terreno próximo aos mangues da comunidade de São Bráz para servir de depósito de lixo. O chorume, produto da decomposição do lixo, não se restringe a propriedade locada, contaminando lençóis freáticos e a terras do entorno. Conforme apontado por Carvalho e Schultz (2014), conflitos envolvendo lixões e aterros sanitários são casos clássicos de racismo ambiental, uma vez que sua alocação elege áreas majoritariamente habitadas por grupos étnico-raciais vulneráveis e de baixa renda ${ }^{16}$. Nessa lógica, transfere-se para as populações mais fragilizadas os custos sociais e ambientais da produção capitalista e do atual modelo de desenvolvimento e consumo. Essas zonas de sacrifício, geralmente são destituídas de serviços públicos e infraestrutura, estando distantes dos locais de habitação dos setores mais privilegiados da sociedade.

No caso em questão, observam-se todas essas características: uma localidade afastada do perímetro urbano, não tanto pela distância, mas pela precariedade da oferta de transporte, habitada predominantemente por famílias negras pobres, com poucos anos de estudo, escassos equipamentos sociais e que não possuem título de propriedade das terras em que vivem. Como é possível perceber pelas situações elencadas, a posse precária de seu território (que abrange terra, mangues, mar e ilhas) e a morosidade na regularização da mesma (apenas o relatório antropológico foi elaborado até então ${ }^{17}$ ) facilita as ações de esbulho, contaminação ou de impedimento de acesso perpetradas por empresas ou pelo próprio Estado ao longo dos anos.

O Estaleiro Enseada do Paraguaçu, estimado em 2 bilhões de reais, consiste numa unidade industrial de construção de embarcações, como plataformas e navios para a Petrobrás e a exploração do "pré-sal”, descoberto em 2006. O consórcio responsável pelo projeto foi composto pelas empresas Odebrecht, OAS, UTC Engenharia (em 2010) e Kawasaki (em 2012). Considerado um dos maiores empreendimentos da iniciativa privada na Bahia e na indústria naval brasileira, ele demandou a contratação de mais de sete mil operários até a paralisação de sua construção em 2015 devido a suspensão de repasses financeiro da Sete Brasil, seu principal cliente, e a prisão dos diretores da OAS e UTC no âmbito da Operação Lava-Jato ${ }^{18}$. O Estaleiro faz divisa com a Comunidade Remanescente de Quilombo da Enseada e com a Reserva Extrativista Marinha Baia do Iguape (CARVALHO e HEIMER, 2015; CARVALHO 2016b).

Como ele foi instalado em uma área que originalmente pertencia a Resex, sua poligonal ${ }^{19}$ foi alterada para comportálo sem debate com as comunidades de pescadores e lavradores do entorno, dentre as quais a maioria é quilombola, e sem consulta ao Conselho Gestor da unidade de conservação. Além disso, ocorreu uma ampliação da porção terrestre da reserva abrangendo parte do território quilombola de São Francisco do Paraguaçu, o que trouxe novos problemas ao processo de

16 Na totalidade das situações analisadas pelos autores a partir do mapeamento realizado pela FIOCRUZ, a localização dos lixões encontra-se próxima a bairros periféricos, habitados por populações pobres e majoritariamente negras.

17 O relatório antropológico é uma das peças do Relatório Técnico de Identificação de Delimitação (RTID) do território quilombola. Esta peça só se torna pública e pode gerar efeitos legais com a finalização do RTID. Sendo assim, sua simples produção não produz nenhuma proteção ou garantia territorial a coletividade em questão.

18 Investigação da Polícia Federal (PF), deflagrada em março de 2014, que apura as suspeitas de lavagem de dinheiro de pessoas físicas e jurídicas, pagamento de propinas a políticos, caixa 2 para financiar partidos aliados do governo, corrupção de agentes públicos, sonegação fiscal, evasão de divisas e desvios de recursos públicos da Petrobrás. Para saber mais: http://g1.globo.com/políitica/operacao-lava-jato/inforgrafico.html

19 Perímetro formado pela ligação entre diversos pontos georreferenciados. É o nome que se dá ao desenho cartográfico dos limites da área da resex. 
regularização territorial vivenciado por essa coletividade (CARVALHO e HEIMER,2015; CARVALHO, 2016b).

A área incorporada consiste num núcleo urbano habitado por 450 famílias e conta com praça, escola e posto de saúde, engloba as propriedades dos fazendeiros que tem demonstrado maior contrariedade ao processo de regularização quilombola seja através de recursos administrativos, seja através de ações judiciais. Com a sobreposição, as desapropriações não serão mais atribuição do INCRA, mas sim do Instituto Chico Mendes de Conservação da Biodiversidade (ICMBio), órgão ligado ao Ministério do Meio Ambiente (MMA) (CARVALHO e HEIMER, 2015; CARVALH0, 2016b).

De acordo com o órgão ambiental, ele tem um passivo de 10 milhões de hectares de terras a regularizar em unidades de conservação no país, orçamento diminuto e número de funcionários insuficientes para a tarefa. O que nos leva a crer que a regularização fundiária por esta instituição seria tão ou mais morosa do que pelo INCRA. Outrossim, essa porção do território não poderá mais ser titulada em nome da associação quilombola como anteriormente previsto, tornando-se propriedade da União sob concessão de uso as comunidades tradicionais existentes no interior da resex. Desse modo, é possível que mesmo após desapropriados, alguns fazendeiros pleiteiem a permanência no local, e que moradores quilombolas que não desenvolvem atividades extrativistas tenham dificuldade em obter esse privilégio (CARVALHO e HEIMER, 2015; CARVALHO, 2016b).

A discussão do plano de manejo em São Francisco do Paraguaçú já tem delineado novos conflitos, agora entre quilombolas e o ICMBio. No interior da unidade de conservação não é possível criar animais de grande porte (como bois, vacas e cavalos) e a expansão ou construção de edificações precisa da permissão do órgão ambiental. Muitas pessoas criam animais desse tipo no local e dependem dessa atividade para o seu sustento. Assim como as reformas ou construção de casas são extremamente frequentes no povoado para acompanhar o crescimento das famílias. Desse modo, a inclusão na resex não proporcionou proteção as moradias quilombolas e ao seu modo de vida como alegado pelo ministro do MMA para modificar a área da unidade de conservação, mas impõe restrições que são incompatíveis com as necessidades do grupo para reproduzir-se social e culturalmente (CARVALHO e HEIMER, 2015; CARVALHO, 2016b).

A alteração da poligonal foi considerada uma medida necessária para o empreendimento, mas os efeitos dela não foram contabilizados como impactos no Estudo de Impacto Ambiental /Relatório de Impacto ao Meio Ambiente (EIA/ RIMA) do estaleiro ainda que já fosse de conhecimento público a demanda territorial do grupo e a sobreposição pudesse ser precocemente identificada. Além disso, a mudança foi executada sem consulta prévia a coletividade, conforme preconiza a Convenção 169 da Organização Internacional do Trabalho, sobre Povos Indígenas e Tribais, da qual o Brasil é signatário através do decreto presidencial 5.051, de 19 de abril de 2004. Mesmo assim, seus representantes se posicionaram contrários a modificação do perímetro da reserva em inúmeras oportunidades (CARVALHO e HEIMER, 2015; CARVALHO, 2016b).

Tal contexto evidencia que, mesmo nos casos em que existe legislação protegendo os interesses das comunidades tradicionais, e das comunidades remanescentes de quilombos em particular, prevalece o ideal de desenvolvimento e a inexorabilidade dos projetos de intervenção territorial, que resulta na limitação dos estudos de proposição de medidas paliativas para a mitigação e compensação dos danos derivados do projeto, configurando um paradigma de adequação ambiental (ZHOURI e GESTA, 2013)

Como apontamos anteriormente, no início dos anos 2000 as coletividades quilombolas tinham demandado alteração da poligonal da RESEX para proteção de seus territórios, sem lograr sucesso. A época o órgão ambiental responsável alegou que a reserva era majoritariamente aquática e que portanto não deveria incorporar novas áreas terrestres. Uma década depois, diante da premissa de que um estaleiro naval teria que ser instalado no local, a mudança da poligonal é feita e recai sobre um perímetro terrestre densamente habitado, sob a pretensa alegação de que deste modo se estaria protegendo um patrimônio histórico e cultural quilombola. Quando a proteção estatal é requerida pelos próprios grupos, ela é negada tendo por base 
“critérios técnicos" que não são levados em consideração no segundo momento. Quando ela é concedida, ocorre a revelia dos sujeitos e se materializa em toda a sorte de restrições e obstáculos a efetivação de seus direitos. Nos dois contextos, as comunidades remanescentes de quilombos são prejudicadas pelo racismo institucional e ambiental que permeia esses procedimentos.

\section{CONSIDERAÇÕES FINAIS}

Conforme publicação de Terra de Direitos e Coordenação Nacional de Articulação das Comunidades Negras Rurais Quilombolas - CONAQ (2018), desde a promulgação da Constituição Federal em 1988, apenas 116 títulos de terras foram expedidos em prol das comunidades remanescentes de quilombos no país, sendo que nenhum deles foi no Recôncavo da Bahia. Mesmo com o julgamento da Ação Direta de Inconstitucionalidade n. 3.239 pelo Supremo Tribunal Federal, reafirmando a legalidade do Decreto 4.887/2003, na medida em que a política de regularização dos territórios quilombolas avançou houve uma drástica diminuição dos recursos financeiros paras atividades meio e desapropriações levadas a cabo pelo Instituto Nacional Colonização e Reforma Agrária. A morosidade e interpretações jurídicas refratárias aos direitos quilombolas tornam o sistema de justiça mais uma barreira a regularização territorial e se somam ao racismo institucional e ambiental perpetrado pelo Estado e empresas.

No caso específico da Bahia, a publicação de Terra de Direitos e CONAQ aponta para alguns fatores que seriam motivadores do acirramento dos conflitos e da violação de direitos e violência contra quilombolas. Dentre eles, destaca-se o apoio das duas últimas gestões estaduais a projetos de desenvolvimento ligados ao Plano de Aceleração do Crescimento (PAC) que se expressa através da flexibilização da legislação ambiental e da criminalização das mobilizações dessas comunidades contra esses empreendimentos que vão desde construção de estradas, expansão da atividade mineradora, instalação de estaleiros para produção de plataformas e embarcações navais, implantação de ecoturismo de luxo, dentre outros.

A análise dos conflitos vivenciados pelas comunidades remanescentes de quilombos do Recôncavo no decorrer dos seus processos de regularização territorial demonstra que danos causados por projetos desenvolvimentistas executados em décadas anteriores somam-se aos atuais. Apesar da existência de leis e políticas especificamente voltadas para a questão, não há garantias de que os pleitos dessas coletividades sejam atendidos e seus direitos respeitados quando estão em jogo interesses de grandes proprietários de terras e empreendimentos privados de interesse estatal. O que nos leva a concluir que para que tais políticas afirmativas tenham sucesso precisam estar articuladas com outras iniciativas que enfrentem o racismo institucional e ambiental que obstaculiza constantemente a sua efetivação. A realização de pesquisas de cunho qualitativo, em especial etnográfico, que desnaturalizem e revelem os dispositivos, mecanismos, lógicas e práticas que perpetuam o racismo nessas dimensões são contribuições valiosas para subsidiar estratégias de enfrentamento da questão. 


\section{REFERÊNCIAS BIBLIOGRÁFICAS}

BERTUSSI, Mayra Lafoz. "Faxinais: um olhar sobre a territorialidade, reciprocidade e identidade étnica". In: ALMEIDA, Alfredo Wagner Berno de; SOUZA, Roberto Martins de (Orgs.). Terras de Faxinais. Manaus: Edições da Universidade do Estado do Amazonas (UEA), 2009.

CARVALHO, Ana Paula Comin de. Reconhecimentos dos direitos quilombolas na Bahia: Balanços e Perspectivas. Trabalho apresentado na $29^{\circ}$ Reunião da Associação Brasileira de Antropologia. Natal/UFRN, ago. 2014.

CARVALHO, Ana Paula Comin de; HEIMER. MIchael. Análise dos impactos do Estaleiro Enseada do Paraguaçu, Maragojipe/BA, com o auxílio da Geotecnologia. Trabalho apresentado no IV Congresso Latino Americano de Antropologia. Cidade do México/ UNAM, out. 2015.

CARVALHO, Ana Paula Comin de. Comunidades Remanescentes de Quilombo na Bahia: conflitos territoriais e articulações identitárias. In: OLIVEIRA, Rosy et al (Orgs). Territorialidades negras em questão:conflitos, lutas por direitos e reconhecimento. Editora UFRB/FT/MC\&G Editorial, Brasília, 2016a.

CARVAlHO, Ana Paula Comin de. Tecnologias de governo, regularização de territórios quilombolas, conflitos e respostas estatais. In: Horizontes Antropológicos. Porto Alegre, ano 22, n. 46, p. 131-157, jul./dez. 2016b

CARVALHO, Márcia Aparecida e SCHULTZ, Gabriel. Conflitos envolvendo lixões e aterros sanitários no Brasil: casos clássicos de injustiça ambiental. In:Simpósio Brasileiro de Saúde e Ambiente: Desenvolvimento, conflitos territoriais e saúde: ciência e movimentos sociais para a Justiça ambiental nas políticas públicas, 2, ABRASCO, Belo Horizonte, 12-22 outubro de 2014

CRUZ, Ana Paula Batista da Silva. Costurando os retalhos: um estudo sobre a comunidade Santiago do Iguape. Paper apresentado no III EBECULT. UFRB/Cachoeira, 2012.

FILHO, Walter Fraga. Encruzilhadas da liberdade: Histórias de escravos e libertos na Bahia (1870- 1910). Campinas: Editora da Unicamp, 2006.

GELEDÉS. Racismo Institucional. Uma abordagem conceitual. ONU Mulheres.

HERCULANO, Selene. O clamor por justiça ambiental e contra o racismo ambiental. In: Revista de Gestão Integrada em Saúde do Trabalho e Meio Ambiente. v.3, n.1, Artigo 2, jan./ abril 2008.

O’DWYER, Eliane C. "O quilombo e as fronteiras da antropologia". In.: Revista Contemporânea de Antropologia - Antropolítica. Universidade Federal Fluminense (UFF), vol. 19, 2005.

PORTO, Marcelo Firpo; PACHECO, Tania; LEROY, Jean-Pierre. Injustiça ambiental e saúde no Brasil: o Mapa dos conflitos. Rio de Janeiro: Editora Fiocruz, 2013.

Terra de Direitos; Coordenação Nacional de Articulação das Comunidades Negras Rurais Quilombolas (Orgs). Racismo e violência contra quilombolas no Brasil. Curitiba: Terra de Direitos, 2018

SCHWARTZ, Stuart. Segredos internos: Engenhos e escravos na sociedade colonial. São Paulo: Companhia das Letras, 1988.

ZAGATTO, Bruna Pastro. Sobreposições territoriais no Recôncavo Baiano: A Reserva Extrativista Baia do Iguape, Territórios Quilombolas e Pesqueiros e Polo Industrial Naval. In: RURIS. v. 7, n.2, set. 2013.

ZHOURI, Andréa; GESTA, Raquel Oliveira. Conflitos entre desenvolvimento e meio ambiente no Brasil: desafios para a antropologia e os antropólogos. In: Desafios da Antropologia Brasileira. Bela Feldman-Bianco (Org.). Brasília. ABA, 2013. 